7. Reprod. Fert. (1973) 33, 513-517

\title{
CHANGES OF $\left(\mathrm{Ca}^{2+}-\mathrm{Mg}^{2+}\right)$-ADENOSINE- TRIPHOSPHATASE ACTIVITY IN RAT TESTIS THROUGHOUT MATURATION
}

\author{
G. DELHUMEAU-ONGAY, R. TREJO-BAYONA \\ AND L. LARA-VIVAS \\ División de Biología de la Reproducción, Departamento de Investigación Cientifica, \\ I.M.S.S.-Apartado Postal 73-032-México 73, D.F.
}

(Received 12th September 1972)

Marked changes in the pattern of energy metabolism occur in rat testis throughout maturation (Free, 1970). The mature testis, as compared with the immature one, has a lower $\mathrm{QO}_{2}$ (Tepperman, Tepperman \& Dick, 1949; Leiderman \& Mancini, 1968) and a different rate of aerobic and anaerobic glycolysis (Tepperman \& Tepperman, 1950; Leiderman \& Mancini, 1968). Adult testis utilizes glucose to a greater extent (Tepperman et al., 1949) and ATP production is primarily dependent upon glucose metabolism in the mature but not in the prepuberal testis (Means \& Hall, 1968). On the other hand, both adult (Tice \& Barrnett, 1963; Setchell, Smith \& Munn, 1972) and immature (Hollinger, 1971) rat testes have been shown actively to hydrolyse ATP. However, the relationship of the rate of ATP catabolism to maturation is not clear. In the present communication, the pattern of the enzymatic hydrolysis of ATP by rat testis as a function of age is reported.

Fifteen groups by age, each consisting of three to eight albino rats of the Wistar strain, were used in the study. The rats were killed at the same hour of the morning by cervical dislocation followed by decapitation and exsanguination. Testes were immediately removed and rinsed in ice-cold twice distilled water. After removal of the tunica albuginea, testes were pooled to prepare a $10 \% \mathrm{w} / \mathrm{v}$ aqueous homogenate with a Potter-Elvehjem homogenizer provided with a loose Teflon pestle. The homogenate was then filtered through glass wool.

The method essentially described by Bonting, Simon \& Hawkins (1961) was used to measure ATP hydrolysis. Bonting's medium A was used for the incubation, which was carried out at $37^{\circ} \mathrm{C}$ (Text-fig. 1). A 10-min pre-incubation without ATP was routinely performed in order to hydrolyse endogenous substrates. The reaction was started by the addition of ATP. All the incubations were run in quadruplicate and $0.5-\mathrm{ml}$ aliquots were withdrawn at $30 \mathrm{sec}$, 1 and $2 \mathrm{~min}$ after the addition of ATP. The reaction was stopped by $2.5 \mathrm{ml}$ ice-cold $6 \%$ perchloric acid. To separate zero-time aliquots, the substrate was added after perchloric acid. All the aliquots were allowed to stand for $30 \mathrm{~min}$ at $0^{\circ} \mathrm{C}$ and were centrifuged. Inorganic phosphate $(\mathrm{Pi})$ was determined in the supernatant by the method of Bonting et al. (1961). Reported values are the 
means of twelve phosphate determinations with their corresponding standard deviations. The protein content of the homogenates was determined by the method of Lowry, Rosebrough, Farr \& Randall (1951).

The pattern of the enzymatic hydrolysis of ATP as a function of age is shown in Text-fig. 1. Twenty-four hours after birth, the enzymatic activity was already present. From the first week of life, it continuously increased until maximal values were attained at 21 to 24 days of age. These 3 weeks correspond to the appearance and differentiation of spermatogonia and spermatocytes, according to Clermont \& Perey (1957), and to the observations of Sosa, Altamirano, Hernández \& Rosado (1972) on the strain of rats used in the present work. After the 24th day of life, at ages corresponding to the appearance and further differentiation of spermatids, there was a statistically significant $(P<0.001)$ negative slope in the enzymatic activity. Stable lower values were

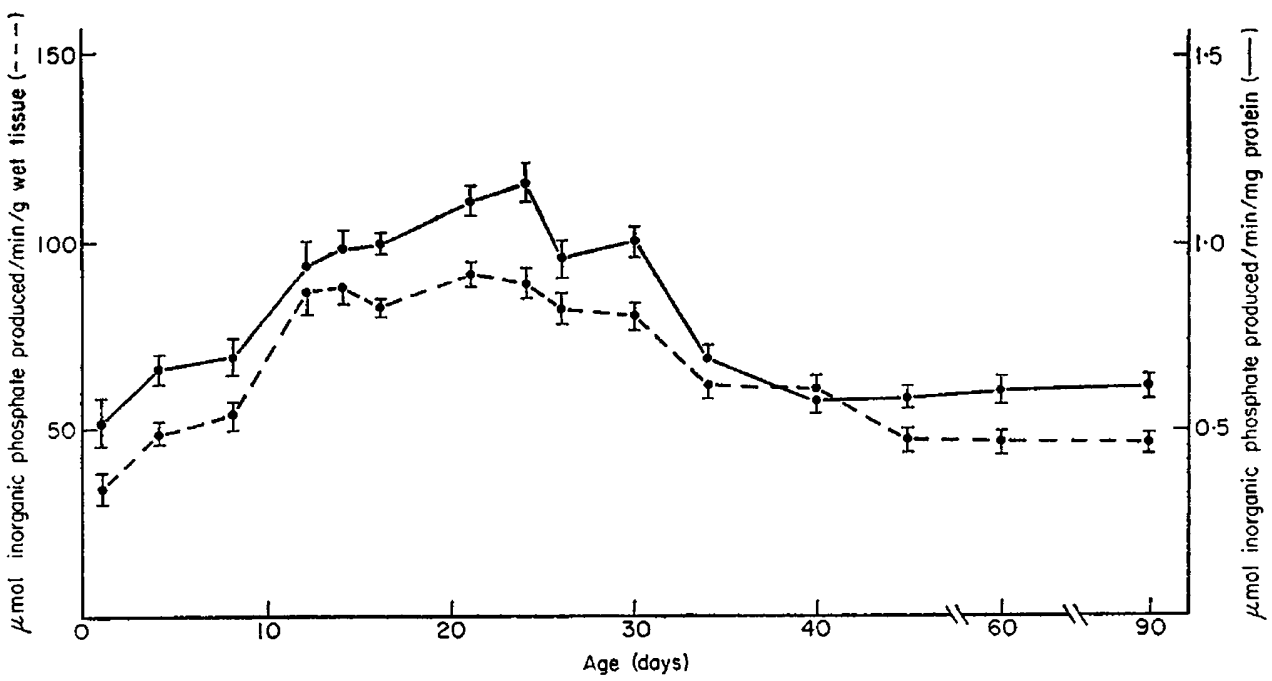

TexT-FIG. 1. Enzymatic hydrolysis of ATP by rat testis as a function of age. The incuba-

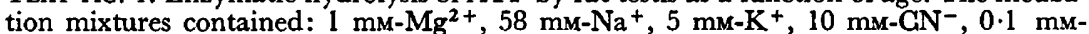
EDTA, 157 mm-Cl- 2 mM-ATP, 92 mm-tris (hydroxymethylamino methane) buffer $(\mathrm{pH} 7.5)$ and $0.1 \mathrm{ml}$ total homogenate $(0.6$ to $1.2 \mathrm{mg}$ protein) per $\mathrm{ml}$.

reached at the 45 th day of age when spermatozoa started to appear. These levels were maintained thereafter throughout adulthood.

Since Kormano (1967) has shown that the testis/body temperature difference changes with age, it seemed important to investigate the effect of the incubation temperature on the enzymatic activity at various ages. Testis homogenates from groups of rats aged 20,30, 35 and 60 days were incubated at $0,20,30,33$, $35,37,40$ and $50^{\circ} \mathrm{C}$ (experimental conditions as described in Text-fig. 1). Within each age group, no significant differences were observed in the enzymatic activities over the temperature range from 33 to $40^{\circ} \mathrm{C}$. Thus, the incubation temperature of $37^{\circ} \mathrm{C}$, non-physiological for testes from certain age groups, did not affect the results shown in Text-fig. 1 .

In order to determine whether the enzymatic hydrolysis of ATP was specific or not and whether the observed chronological changes of the enzymatic activity 
were quantitative or qualitative in nature, some preliminary cation-dependence and substrate-specificity studies were undertaken. Testes from both adult and immature rats were used in these studies.

(a) Cation dependence. Using $2 \mathrm{mM}$-ATP as a substrate, $\mathrm{Na}^{+}, \mathrm{K}^{+}$, EDTA and cyanide could be eliminated from the original Bonting's medium without any detectable change in the activity. An absolute requirement of either $\mathrm{Mg}^{2+}$ or $\mathrm{Ca}^{2+}$ was observed, $5 \mathrm{~mm}$ being the optimal concentration for both divalent cations. When increasing amounts of $\mathrm{Ca}^{2+}$ were added to the incubation mixture containing $5 \mathrm{~mm}-\mathrm{Mg}^{2+}$, the activity was inhibited $(40 \%$ at equimolar concentrations, $50 \%$ at a $2: 1 \mathrm{Ca}^{2+} / \mathrm{Mg}^{2+}$ ratio). This effect was similar to the one reported in placental ATPase (Shami \& Radde, 1972).

(b) Substrate specificity. Text-figure 2(a) shows that, in the presence of magnesium ions, adult rat testis homogenates were able to hydrolyse ATP, GTP, GTP and UTP at similar rates. Hydrolysis of ADP took place at a lower
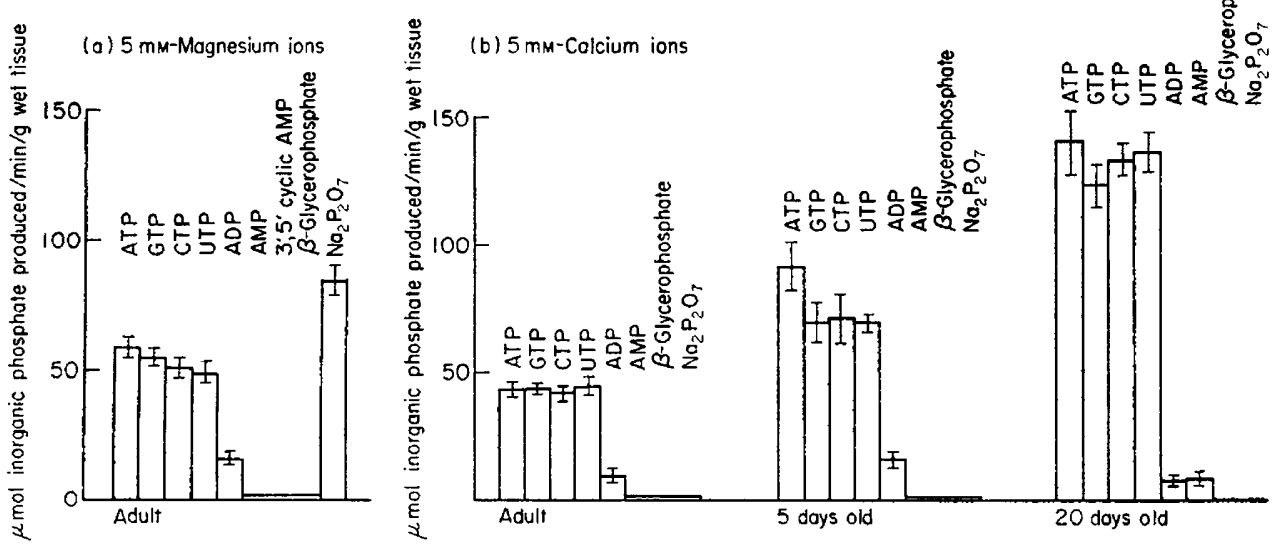

(b) $5 \mathrm{~mm}$-Colcium ions

Texr-FIG. 2. Enzymatic hydrolysis of various substrates by immature and adult rat testis. The incubation mixtures contained: either $5 \mathrm{~mm}-\mathrm{Mg}^{2+}$ (a) or $5 \mathrm{~mm}-\mathrm{Ca}^{2+}$ (b), $156 \mathrm{mM}^{-\mathrm{Cl}^{-}}, 2 \mathrm{~mm}$-substrate, $146 \mathrm{~mm}$-tris (hydroxymethylamino methane) buffer (pH 7.5 ) and $0.1 \mathrm{ml}$ total homogenate per $\mathrm{ml}$.

rate. No hydrolytic activity was observed towards AMP, 3', 5' cyclic AMP or $\beta$-glycerophosphate, but a very high inorganic pyrophosphatase activity was encountered. This enzyme became saturated at $0.5 \mathrm{~mm}$-substrate concentration and showed an absolute requirement for $\mathrm{Mg}^{2+}$ in an equimolar pyrophosphate/magnesium ratio. It was completely inhibited by $2 \mathrm{~mm}-\mathrm{NaF}$ and had no activity whatsoever when calcium was used instead of magnesium. These properties shown by rat testis pyrophosphatase were markedly different from those described for inorganic pyrophosphatase from bull semen (Heppel \& Hilmoe, 1951).

To determine whether ATP was hydrolysed by a phosphatase or by an organic pyrophosphatase, it was important to avoid inorganic pyrophosphatase activity. Determinations were therefore performed in the presence of $5 \mathrm{~mm}$ $\mathrm{Ca}^{2+}$ instead of $\mathrm{Mg}^{2+}$, since the pattern of nucleotide hydrolysis by adult 
testis homogenates was similar with either cation (Text-fig. $2 a$ and b). The inclusion of inorganic pyrophosphatase activity could have also been avoided by using fluoride since this did not appreciably inhibit ATP hydrolysis.

Text-figure 2(b) shows that the pattern of nucleotide hydrolysis was qualitatively similar in the adult and the immature testis, suggesting that the observed activity is mainly one of a $\left(\mathrm{Ca}^{2+}-\mathrm{Mg}^{2+}\right)$-dependent ATPase. It was, however, twice as great in the 6-day-old rat testis and over three times as great in the 20-day-old rat as in the adult testis.

Nucleoside diphosphatase showed only a slight increase in activity in the 5-day-old rat and 5'-nucleotidase was only apparent in the 20-day-old rat.

A high activity of ATPase that could be stimulated by either $\mathrm{Ca}^{2+}$ or $\mathrm{Mg}^{2+}$ but not by $\mathrm{Na}^{+}$or $\mathrm{K}^{+}$was found to occur in rat testis at all ages from birth to maturity. The activity, however, showed marked quantitative changes as a function of the age of the animal. During the first 3 weeks of life, a continuous increase in activity was encountered. This observation is consistent with a high energy requirement for the very active proliferation of the germinal epithelium, as previously suggested (Free, 1970; Hollinger, 1971). Throughout the ages corresponding to the appearance and differentiation of spermatids, ATPase activity continuously decreased until the 7 th week of life. A cellular dilution effect could be evoked to interpret this finding. It may also suggest that during spermiogenesis, the testis progressively changes its energy metabolism until a different and stable pattern is attained in early maturity. In fact, previous studies have shown marked differences between the metabolic energy pattern of adult and immature testis in terms of $Q^{\mathrm{O}_{2}}$ (Tepperman et al., 1949; Leiderman \& Mancini, 1968), rate of glycolysis (Tepperman \& Tepperman, 1950; Leiderman \& Mancini, 1968), glucose utilization (Tepperman et al., 1949), ATP production (Means \& Hall, 1968) and now ATP hydrolysis.

It has been suggested that most of the differences observed in energy metabolism before and after maturation involve the seminiferous tubules rather than the interstitium (Leiderman \& Mancini, 1968; Leiderman, 1969; Free, 1970). Since no effort was made in this study to separate these tissues, any suggestion at this stage concerning the cellular localization of the $\left(\mathrm{Ca}^{2+}-\mathrm{Mg}^{2+}\right)$-ATPase would be speculative. Further experimental work is now in progress to clarify this point.

This work was partially supported by a grant from the Ford Foundation.

\section{REFERENGES}

Bonting, S. L., Srmon, K. A. \& Hawkins, N. M. (1961) Studies on sodium-potassium-activated adenosine triphosphatase. 1. Quantitative distribution in several tissues of the cat. Archs Biochem. Biophys. 95, 416.

Glermont, Y. \& Perey, B. (1957) Quantitative study of the cell population of the seminiferous tubules in immature rats. Am. F. Anat. 100, 241.

Free, M. J. (1970) Carbohydrate metabolism in the testis. In: The Testis, Vol. II, p. 125, Eds. A. D. Johnson, W. R. Gomes and N. L. VanDemark. Academic Press, London.

Hepper, L. A. \& Hilmoe, R. J. (1951) Purification of yeast inorganic pyrophosphatase. 7. biol. Chem. $192,87$.

Hollinger, M. A. (1971) Metabolism of ATP by testis mitochondria of 25-day-old rats. F. Reprod. Fert. 25, 443. 
Kormano, M. (1967) Development of the rectum-testis temperature difference in the post-natal rat. 7. Reprod. Fert. 14, 427.

Leiderman, B. (1969) Consumo de oxígeno y producción de ácido láctico de células germinales aisladas "in vitro" de testículo de rata. Revta Soc. argent. Biol. 45, 57.

Lemerman, B. \& Mancini, R. E. (1968) Aerobic and anaerobic lactate production in the prepuberal and adult rat testis. Proc. Soc. exp. Biol. Med. 128, 818.

Lowry, O. H., Rosebrough, N. J., Farr, A. L. \& Randall, R. J. (1951) Protein measurement with the Folin phenol reagent. F. biol. Chem. 193, 265.

Means, A. R. \& Hall, P. F. (1968) Protein biosynthesis in the testis: II. Role of adenosine triphosphate (ATP) in stimulation by glucose. Endocrinology, 83, 86.

Setchell, B. P., Smith, M. W. \& Munn, E. A. (1972) The stimulation by bicarbonate of adenosine triphosphatase activity in the seminiferous tubules of rodents and the lack of effect of ouabain. 7. Reprod. Fert. 28, 413.

Shami, Y. \& Radde, I. C. (1972) The effect of the $\mathrm{Ca}^{2}+/ \mathrm{Mg}^{2+}$ concentration ratio on placental $\left(\mathrm{Ca}^{2+}-\mathrm{Mg}^{2+}\right)$-ATPase activity. Biochim. biophys. Acta, 255, 675 .

Sosa, A., Altamirano, E., Hernández, P. \& Rosado, A. (1972) Developmental pattern of rat testis hexokinase. Life Sciences, 11, Part II, 499.

Tepperman, H. M. \& Tepperman, J. (1950) Glucose utilization in vitro by normal adult, immature and cryptorchid testis. Endocrinology, 47, 459 .

Tepperman, J., Tepperman, H. M. \& Dick, H. J. (1949) A study of the metabolism of rat testis in vitro. Endocrinology, 45, 491.

Tice, L. W. \& BARRNETr, R. J. (1963) The fine structural localization of some testicular phosphatases. Anat. Rec. 147, 43. 